\title{
Don't Pester Me! Unwanted Upgrade Innovation
}

\author{
Yazhen Xiao and Jelena Spanjol
}

\begin{abstract}
Consumers encounter incremental innovations that aim to improve currently owned products on a daily basis. This type of innovation, which we term upgrade innovation, can improve user experience, product security, and the overall performance of the owned product. Yet, upgrade innovation is not always appreciated by customers, at times leading customers to reject it or ignore its availability. In an extreme non-adoption condition, customers may actively seek strategies in order not to be notified the availability of upgrade innovations.

Drawing on extant innovation literature (e.g., Calantone et al. 2006; Davis 1980; Sorescue and Spanjol 2008), we explore the influence of upgrade innovation characteristics on upgrade intention, and investigate two alternative mechanisms: annoyance and anticipated regret that explain why upgrade innovation is sometimes unwanted by product owners. Customers are annoyed at upgrade innovation in that it changes the owned products. Alternatively, they could feel regretful if adopting upgrade innovation that does not bring anticipated benefit, and/or if missing the upgrade innovations that improve owned product. This research is the first to call attention to the impact of annoyance and anticipated regret in upgrade innovation adoption. When customers have strong psychological ownership on owned products, the effect of upgrade innovation on upgrade innovation adoption is expected to be enlarged.

This study contributes to marketing and innovation research in several ways. First, it raises the definition of upgrade innovation on already owned products. Second, it investigates the influence of annoyance, a frequently happening but rarely examined consumption emotion, on product decisions. Last but not least, it explores the role of anticipated regret of adopting and not adopting in innovation adoption.
\end{abstract}

References available upon request.

Y. Xiao $(\bowtie) \cdot$ J. Spanjol

University of Illinois at Chicago, Chicago, IL, USA

e-mail: yxiao21@uic.edu; spanjol@uic.edu

L. Petruzzellis, R.S. Winer (eds.), Rediscovering the Essentiality of Marketing, Developments in Marketing Science: Proceedings of the Academy of Marketing Science, DOI 10.1007/978-3-319-29877-1_96 